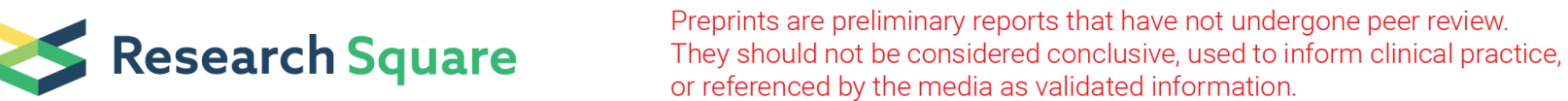

\section{Prevalence and Correlates of Bullying in Physiotherapy Education in Nigeria}

Chidozie Emmanuel Mbada ( $\nabla$ doziembada@yahoo.com )

Obafemi Awolowo University Faculty of Basic Medical Sciences

Idowu Phebean Ogunseun

Obafemi Awolowo University Faculty of Basic Medical Sciences

Francis Oluwafunso Fasuyi

The University of Manchester Faculty of Biology Medicine and Health

Oluwafemi David Adegbemigun

University of Nigeria Faculty of Medical Sciences

Clara Toyin Fatoye

Manchester Metropolitan University

Opeyemi Ayodiipo Idowu

University of Benin

Olubusola Esther Johnson

Obafemi Awolowo University

Adesola Christiana Odole

University of Ibadan College of Medicine

Adaobi Margaret Okonji

Obafemi Awolowo University Faculty of Basic Medical Sciences

\section{Basir Kaka}

Bayero University College of Health Sciences

Francis Fatoye

Manchester Metropolitan University

Research article

Keywords: Bullying, physical therapy, modalities, specialty, Nigeria, Students

Posted Date: March 13th, 2020

DOI: https://doi.org/10.21203/rs.2.21959/v2

License: (c) (1) This work is licensed under a Creative Commons Attribution 4.0 International License. Read Full License 
Version of Record: A version of this preprint was published at BMC Medical Education on April 15th, 2020. See the published version at https://doi.org/10.1186/s12909-020-02019-2. 


\section{Abstract}

Background: Bullying is an unexpressed part and parcel of medical education but it is largely unexplored in physiotherapy. This study assessed the prevalence and socio-demographic correlates of bullying in physiotherapy education in Nigeria.

Methods: Two hundred and nineteen clinical physiotherapy students from three purposively selected Federal Universities in Nigeria participated in this study. Following a cross-sectional design, the Students Perception of Professor Bullying Questionnaire (SPPBQ) was used to obtain information on bullying. The SPPBQ includes a working definition of lecturer bullying followed by other sections inquiring about lecturers bullying experiences. Data was collected on socio-demographic characteristics, bullying experiences and availability of adequate policy and support on bullying. Descriptive and inferential statistics were used analyze data. Alpha level was set at $p<0.05$.

Results: Lifetime and point prevalence of bullying in physiotherapy education were $98.6 \%$ and $99.1 \%$. $94.5 \%$ of the respondents had witnessed physiotherapy students bullying and there was a $100 \%$ rate of 'no attempt' to stop a physiotherapy lecturer from bullying. $38.4 \%$ and $44.7 \%$ of the respondents believed there was adequate school policy and support available on bullying. There was no significant association between bullying and each of age $(\chi 2=0.117, p=0.943)$, gender $(\chi 2=0.001, p=0.974)$, level of study $(\chi 2=0.000, p=0.995)$ and any specific university $(\chi 2=1.343, p=0.511)$.

Conclusion: There is high lifetime and point prevalence of bullying in physiotherapy education in Nigeria, which are largely unchallenged or redressed. Being a clinical physiotherapy student ordinarily predisposes to bullying without necessary contributions of intrinsic and extrinsic factors.

\section{Background}

Bullying is described as the misuse of power or position to persistently criticize and condemn; to openly humiliate and undermine an individual's ability until they become so fearful that their confidence crumbles and they lose belief in themselves [1], leaving the victim[s] feeling hurt, vulnerable, angry or powerless [2]. Bullying exists in various forms and in various places. Specifically, workplace bullying is commonplace and diverse in nature [3, 4]. Workplace bullying may involve verbal, physical or psychological act which may be encouraged by imbalance of power between the superiors and the subordinates $[5,6]$ and in some other instances it may occur between coworkers or from subordinates to superiors [7, 3]. Also, there is substantial literature on occupational bullying in the health sector [8-10], especially, among physicians [11-13], nursing practitioners [14-16], dental practitioners [17] and health care administrators [18].

Similar to the foregoing, bullying in the context of health professions education has been documented. As a type of school bullying, it is often characterized by verbal, physical, sexual or emotional harassment or in some cases, a cyberbullying $[19,20]$. The United Nations Educational, Scientific and Cultural Organization (UNESCO) [21] submits that gender norms, social norms and the peculiarity of the context 
underlie school bullying. Specifically, discriminatory gender norms promote male dominance and the suppression of women; while social norms legitimize the authority of lecturers over students [21]. Other authors have documented some other sociodemographic factors such as religion, race and culture to independently or in association promote school bullying [22-24].

Rautio et al [25] assert that the medical student is the worst hit by bullying [25]. Other researchers concur that bullying is one of the critical stressors students in tertiary institutions around the globe face, especially among those training to become health professionals [26-28]. The period of training to become a health professional remains a stressful one; exposing trainees to situations and experiences with appalling implications for their psychological well-being [29]. In this period, while having to put up with the pressure of a demanding and competitive health professional education, many students are harassed and bullied. The disparagement and belligerence that bullying instills may explain the suicidal ideation of some students and account for unprofessional conducts by some health professionals during practice [29]. Though this topic has been in discussion for ages, especially among medical and nursing students [28-31], it is still one of the least prioritized concerns in the education of other health professionals.

Lecturer bullying may have severe consequences for student victims, including negative psychosocial and behavioral outcomes such as loss of trust, feelings of hopelessness and depression, oppositional behavior and increased fighting amongst peers [32]. Therefore, lecturer bullying remains a "delicate issue" [33] and indeed, an extant issue that cannot be denied [34-38]. Research on professor/instructor bullying is important given findings that university students' perception of rapport with their professors/instructors predicts motivation, perceptions of learning and perceived grades [39]. In all of these, not much is known about bullying in the physiotherapy practice and education. Seager [40] submit that there is very limited research on bullying in the physiotherapy profession, as only one United Kingdom study was found on bullying among physiotherapy students [41]. Thus, the issue of bullying from the perspective of the physiotherapy profession, as well as from the sub-Saharan African context seems to have drawn little or no attention, except for few studies reporting on workplace bullying within the African context [42, 43]. Unfortunately, based on empirical reports, Nigeria, like most other countries in sub-Sahara Africa is notorious for human right abuses [44, 45]. The UNESCO [21] submits that 'schools and the education system also operate within the context of wider social and structural factors and may reflect and reproduce environments that do not protect students from violence and bullying.' Anecdotally, bullying is a common occurrence in the Nigerian setting, which may be suggestive of the pattern in the wider social context. To our knowledge there seems to be no local unpublished research reports which highlight this knowledge gap. Therefore, this study assessed the prevalence and socio-demographic correlates of bullying in physiotherapy education in Nigeria.

\section{Methods}

Respondents for this cross-sectional study were purposive clinical physiotherapy students from the three out of the six Federal Universities where physical therapists are trained in Nigeria. These institutions are the University of Ibadan (UI), University of Lagos (UNILAG) and the Obafemi Awolowo University (OAU). 
These institutions are the oldest and foremost training institutions for physiotherapy in Nigeria. In addition, these institutions have longstanding and experienced faculties in the Nigerian context.

Respondents in this study were students in the clinical levels (i.e. year three and above) of the current fiveyear baccalaureate programme in Nigeria. Based on available sample frame of all students in the clinical level of the selected university, a population of 379 was obtained. A sample size formula by Yamane [46] $\mathrm{n}=\mathrm{N} / 1+\mathrm{N}\left(\mathrm{e}^{2}\right)$ was used to calculated the sample size. Where $\mathrm{n}$ is sample size, e is level of error tolerance and $\mathrm{N}$ is the population size. Thus, $\mathrm{n}$ obtained was 181 , however, allowing for $10 \%$ nonresponse, a total of 189 was estimated.

Students Perception of Professor Bullying Questionaire (SPPBQ) was used to assess bullying among the respondents. The SPPBQ contains a working definition of professor/lecturer bullying followed by three questions inquiring about lecturers bullying experiences [47, 48].The developers of the tool modeled it after earlier tools by Chapell et al [34] on teacher and professor/instructor/peer bullying experiences. In addition, was the Negative Acts Questionnaire - Revised (NAQ-R) which was designed to assess workplace bullying [5]. The NAQ-R encompassed three underlying factors (personal, work-related and physically intimidating forms of bullying) and also generated a single item measure of bullying [5]. The SPPBQ covers three underlying factors, these are personal characteristics, and academic-related and physically intimidating forms of bullying. Questions on the tool address specific behaviors and answer choices on a Likert scale for frequency, from never to daily. Results of the psychometric evaluation of the tool indicates a Cronbach's coefficient Alpha that was satisfactory for its various components (academic bullying ( $a=.901)$, personal bullying ( $\alpha=.883)$, as well as the global component for all 11 items $(a=$ .909). In addition, the criterion validity of the SPPBQ was satisfactory for academic bullying $(r=.591, p<$ $.001)$ and personal bullying $(r=.289, p<.001)$ components.

The part of the SPPBQ that bothered on professor/instructor bullying experiences was utilized in this study. The aspects of the tool exploring peer bullying experiences were outside the scope of this study. In addition, in place of the demographic aspect of the questionnaire that sought information on personal characteristics, a proforma was designed to obtain context-specific information. The adapted too

I was pilot tested among 20 clinical physiotherapy students recruited from the OAU, who were not part of the main study. A test-retest analysis of the global components scores of the tool yielded a Spearmen rho value of 0.969 at $p=0.001$. Prior to the test-retest survey, a qualitative group debriefing assessment was carried out where each of the items were read out to judge respondents comprehensibility of the items. It was a consensus that the word 'professor/instructor' be modified to 'physiotherapy lecturer' as it is being commonly used in the study setting. Unlike in some other contexts, where university teachers are referred to as Professors, it is almost insupportable to answer to the name, having not attained the rank. As such, respondents may miss out lecturers of lower ranks in the survey. This survey utilized an in-person, paper and pencil self-administration mode for the collection of data using the questionnaire.

Ethical approval for this study was obtained from the Human Research and Ethics Committee of Institute of Public Health (IPHOAU/12/925), Obafemi Awolowo University, Ile-lfe, Nigeria. Informed consent was 
obtained from all respondents following full disclosure of the purpose of the study. Respondents were assured of anonymity, as no names or personal identifiers were associated with the data. No teaching faculty was involved in data collection process, so as to limit coercive participation, considering the sensitive nature of the study and also considering that in-person mode of questionnaire administration was used in the study.

\section{Statistical analysis}

Descriptive statistics of mean, standard deviation, frequency and percentages was used to summarize data. Based on responses in section B of the questionnaire, 0, 1, 2, 3, 4 were assigned to 'never', 'now and then' 'monthly', 'weekly', and 'daily' respectively. Total obtainable score for the 21 questions was 84 with higher scores indicating high level of bullying. A score of 28 or less, 29 to 56 , and greater than 56 were categorized as mild, moderate and severe bullying respectively. Pearson Chi-square was used to investigate factors associated with bullying. Alpha level was set at $p<0.05$. SPSS version 16.0 (Chicago, Illinois: SPSS) was used to analyse data.

\section{Results}

Table 1 shows the socio-demographic characteristics of the respondents in the study. Most of the respondents were single (98.2\%) and within the age bracket of 20 to 25 years (94.5\%), of Yoruba ethnicity (85.8\%), of Christian religion (79.9\%) and were of the female gender $(51.1 \%)$. The result showed that the mean age of respondents was $21.8 \pm 1.50$. Table 2 shows the frequency distribution on policy and support on bullying. From the result, $37.5 \%$ and $42.7 \%$ of respondents from Obafemi Awolowo University, lle-Ife, Nigeria responded in the affirmative (i.e. yes) to having adequate school policy and support on bullying. Responses on having adequate 'policy' and 'support' on bullying from respondents from University of Ibadan, Nigeria and University of Lagos, Nigeria were $30 \%$ and $48 \%$, and $45.2 \%$ and $45.2 \%$ respectively. In sum, $38.4 \%$ and $44.7 \%$ of the respondents believed there was adequate school policy and support available on bullying.

Table 3 shows the distribution of bullying characteristics of the respondents. $94.5 \%$ of all respondents had witnessed a physiotherapy student been bullied by a physiotherapy lecturer. $98.6 \%$ of all respondents have experienced bullying by a physiotherapy lecturer. $99.5 \%$ of all students who had experienced bullying neither stopped or attempted to stop a physiotherapy lecturer from bullying them. $99.1 \%$ of the respondents had a recent positive history or experience of bullying in their present level by a physiotherapy lecturer, while none of the respondents $(100 \%)$ of the respondents stopped or attempted to stop a physiotherapy lecturer from bullying. Table 4 shows the association between lifetime prevalence of bullying and socio-demographic characteristics of the respondents. The result showed that there was no significant association between bullying and each of age $(p=0.92)$, gender $(0.07)$, ethnicity $(0.50)$, religion (0.06), university (0.22), educational level (0.33), marital status (0.064) of the respondents. Table 5 shows the association between points prevalence of bullying and socio-demographic characteristics of the respondents. Similarly, the result showed no significant association between bullying and each of age 
(0.94), gender (0.97), ethnicity (0.85), religion (0.16), university (0.51), educational level (0.99), and marital status (0.85) of the respondents. Fig 1 shows the total bullying scores of all the respondents. $82.2 \%$ has experienced a mild form of bullying, $15.5 \%$ has experienced a moderate form of bullying while $2.28 \%$ has experienced a severe form of bullying.

\section{Discussion}

This study investigated bullying and its socio-demographic correlates among physiotherapy students in Nigeria. The responding physiotherapy students were mostly females who were within 20 and 25 years bracket. The lifetime prevalence of bullying in this study was $98.6 \%$, while the point prevalence was $99.1 \%$. The high lifetime and point prevalences of bullying observed in this study were comparable to early findings. For example, Clarke and colleagues [49] reported positive history of bullying behaviors (88.72\%) among Canadian clinical undergraduates nursing students. Similarly, other international studies have reported up to $90 \%$ bullying rates among nursing students in the clinical setting [50-52]. On the other hand, relatively lower rates of bullying were recorded in a Turkish and United Kingdom study that stated only more than half ( $60 \%$, and $53 \%$ ) of the respondents were exposed to bullying during their education $[53,54]$. The higher rates of bullying observed in this study may be an indicator of right abuses that are prevalent in the wider society in Nigeria $[55,56]$. According to UNESCO (57) physical and other forms of bullying behaviour in schools' settings is a reflection of the wider social context (57). The UNESCO report also suggests that 'sexual violence and harassment of girls is worse in schools where other forms of violence are prevalent, and in conflict and emergency contexts' (57). The recent media reports on the spates of sexual harassment in the academy in Nigeria [58] may just be a pointer to the extent of bullying that have happened and currently going on in the Nigerian comtext. McEvoy [59] has described lecturer bullying to include sexual harassment and hate crimes. Similarly, UNESCO (21) designates sexual violence, including rape and sexual harassment as a form of bullying.

This study findings showed that $100 \%$ of the physiotherapy students had experienced bullying behaviours in the clinical settings in forms of being humiliated in connection with their course, being ignored and excluded, spreading of gossip and rumors about them, being shouted at or being the target of spontaneous anger or having an offensive remarks made about them by a physiotherapy lecturer. Consistent with this finding is the report of Foster and Colleagues [60], who identified that $90 \%$ of nursing students reported experiencing some form of bullying while on clinical placement. In line with the finding of this study, a report from Turkey revealed that $100 \%$ of nursing students in a surveyed reported being yelled or shouted at, or were behaved toward in an inappropriate, nasty, rude or hostile way, or were belittled or humiliated. In this same study, $83.1 \%$ of the student nurses reported experiencing academic abuse which included being told negative remarks about becoming a nurse; being assigned responsibilities as punishment rather than for educational purposes; and being punished with poor grades or being shown hostility following an academic accomplishment [50]. Supporting these results, a U.S. study which revealed that the most frequently reported behaviors perceived to be bullying included cursing or swearing (41.1\%), inappropriate, nasty, rude or hostile behaviors (41\%) and belittling or 
humiliating behavior (32.7\%) [52]. Moreover, Stevenson and colleagues [53] found that the least frequent negative behavior selected by the students was the threat of actual physical violence.

Social norms and power imbalances in schools promote attitudes and practices that tend to subdue students, support unequal gender norms, as well as bear with violence, including corporal punishment [21]. The use of violence to assert discipline and control in the academy is attributable to social norms that support the authority of lecturers over students, and students who defies or choose not to conform to these norms gets punished through violence and bullying [21]. While, discipline is probably the most difficult and unpleasant part of teaching profession [61-62], however, many traditional approaches to discipline are reported to be negative, punitive and reactive, and results in bad outcomes for all parties involved [63]. Still, corporal punishment is common in Nigeria and is often treated as an integral part of education, holding a place in schools teaching [64] and it is more pronounced in secondary schools than in universities $[65,66]$. It is adducible, that bullying in the Nigerian university setting could be as a result of repression or inhibited tendency to implement corporal punishment that is only permissible at lower school level.

The result of this study has also revealed that a large number of physiotherapy students have witnessed an incidence of a physiotherapy lecturer bullying another physiotherapy student and only a whit of the respondents has ever stopped or attempted to stop a physiotherapy lecturer from bullying them or other physiotherapy students in the college. This is consistent with the findings of Clarke and colleagues [49] who stated that students justified not taking action as a result of experiencing bullying behaviors by making excuses for the poor behavior, minimizing the event and its impact, normalizing the behavior and fearing a poor evaluation. Furthermore, Stevenson and colleagues [53] found that students identified that reporting bullying was not worth the effort, wished not to jeopardize their assessment and that it is something that one must simply adapt with. This is also in line with report by Hoel and colleagues [67] who, in a qualitative study investigating the realities and expectations of nursing students, reported that students defended the poor behavior, to the extent of suggesting that it may serve a purpose or that it was due to pressure and/or workload or previous experiences of bullying. In line with the foregoing, it is an anecdote in the study setting that a lot of students seem to be absorbed in the so called 'culture of silence' where students out of ignorance or for the fear of intimidation refuses to reports or challenge a harassment or a bullying.

This study further investigated the availability of adequate support and policies on bullying in the various universities. The result revealed that there is no significant difference between bullying and the availability of support and polices. Findings among the few studies that examined associations between policy presence and student bullying were mixed, although more non-significant than significant associations were found. At first glance, one may conclude from these findings that the presence of bullying policies does not influence bullying among students; however, the presence of a policy is necessary but is not sufficient to affect bullying behavior. Indeed, after a policy has been adopted, it must be put into practice. The mere adoption or presence of a policy does not mean that it will be immediately and consistently put into practice exactly as intended [68]. However, the veracity of claims on available of 
policies to cub or limit bullying in education may at best be speculative, as anecdotal information among the students so indicate.

The result of this also revealed that there was no significant association between bullying and gender, age, ethnicity, religion, university and educational level of the participants in the study. The lack of a significant association between bullying and the socio-demographic characteristics of the students indicates that those involved in bullying do not tend to choose their targets based on the characteristics of the respondents. This finding is in line with Salin's [69] study indicating that the bullying is enabled by a power imbalance and the low perceived costs of bullying. This study has addressed the prevalence of bullying experiences among clinical physiotherapy students. The study has identified common issues that physiotherapy students face during their education, which leave them feeling powerless and frustrated. A potential limitation of this study may include the non-probability sampling method used, which may impact on the external validity of the findings. Also, the generalizability of the findings is limited to clinical physiotherapy students, especially those from the institutions surveyed. Furthermore, the instrument used in this study was only tested for its reliability and face validity in the pilot study, there is little or no reports on its validity in many studies nor in this current study's setting, and this poses a limitation. This is the first empirical report on bullying in physiotherapy education in Nigeria. This report may serve as a precursor for inquiry into bullying in other health professions education in Nigeria. In addition, the reports have implications for necessary policy guidance on addressing bullying and effecting the required change in the organisational culture in the Nigerian health profession educational setting. In addition, the finding of this study may reveal the gap in the extant policy on bullying and the reality. Thus, a qualitative enquiry into the contextual factors engendering bullying in the academy in Nigeria is recommended.

\section{Conclusion}

There is high lifetime and point prevalence of bullying in physiotherapy education in Nigeria, which are largely unchallenged or redressed. Being a clinical physiotherapy student ordinarily predisposes to bullying without necessary contributions of intrinsic and extrinsic factors.

\section{Declarations}

Ethics approval and consent to participate

This study was approved by the Human Research and Ethics Committee of Institute of Public Health, Obafemi Awolowo University, Ile-Ife, Nigeria. This survey was voluntary and anonymous, every participant signed an informed consent form.

Consent for publication

Not applicable. 
Availability of data and materials

The datasets obtained and used for analysis in this study are available on reasonable request from the corresponding author.

\section{Competing interests}

There is no competing interest

\section{Funding}

There was no funding received for this study.

\section{Authors' Contributions}

CEM (Chidozie Emmanuel Mbada), ACO (Adesola Christiana Odole) and FF (Francis Fatoye) participated in the conception and design of the study. IPO (Idowu Phebean Ogunseun), FOF (Francis Oluwafunso Fasuyi), ODA (Oluwafemi David Adegbemigun) and AMO (Adaobi Margaret Okonji) contributed with the acquisition of data. CEM and IPO conducted data analysis. All authors participated in the interpretation of data and drafting the manuscript. All the above authors, including OAI (Opeyemi Ayodiipo Idowu), OEJ (Olubusola Esther Johnson) and BK (Basir Kaka) drafted and approved the final submission of the manuscript.

\section{Author information}

CEM, BMR (PT) PhD is a Senior Lecturer and Researcher at the Department of Medical Rehabilitation at the Obafemi Awolowo University, Ile-Ife, Nigeria. He is currently the Postgraduate training co-ordinator in the Department.

IPO, BMR (PT) is a Physiotherapist trained at the Obafemi Awolowo University, lle-lfe, Nigeria where she received a Bachelor of Medical Rehabilitation (Physiotherapy). She is currently an intern Physiotherapist at the Federal Medical Centre, Abeokuta, Ogun State, Nigeria.

FOF, MSc PT is a Lecturer and Researcher at the Department of Physiotherapy at the Faculty of Allied Health Sciences, University of Medical Sciences, Ondo, Nigeria.

ODA, MSc PT is a Lecturer and Researcher at the Department of Physiotherapy at the Faculty of Allied Health Sciences, University of Medical Sciences (UNIMED), Ondo, Nigeria. He is currently the undergraduate programme coordinator at the UNIMED.

CTF, MSc is an early career researcher and a doctoral fellow at the Department of Health Professions, Faculty of Health, Psychology and Social Care, Manchester Metropolitan University, United Kingdom.

OAl, BMR (PT) PhD is a Lecturer and Researcher at the Department of Physiotherapy, School of Basic Medical Sciences, College of Medical Sciences, University of Benin, Nigeria 
OEJ, Med, MSc PhD PT was formerly a Senior Lecturer and Researcher with the Department of Medical Rehabilitation at the Obafemi Awolowo University, lle-lfe, Nigeria.

ACO, BMR (PT) PhD is a Senior Lecturer at the Department of Physiotherapy, College of Medicine, University of Ibadan, Nigeria and Honorary Consultant in Physiotherapy at the University College Hospital, Ibadan, Nigeria.

AMO, MSc PT is a Lecturer and Doctoral Fellow at the Department of Medical Rehabilitation at the Obafemi Awolowo University, Ile-Ife, Nigeria.

BK, PhD PT a Senior Lecturer and Researcher at the Department of Physiotherapy, Bayero University, Kano, Nigeria. He is currently the Head of Department at the Institution.

$\mathrm{FF}, \mathrm{PhD}$ is a Professor of Health Economics and Outcomes, as well as the Co-Director for Health, Psychology and Communities ( $\mathrm{HPaC})$ Research Centre at Manchester Metropolitan University, United Kingdom. He is a Physical Therapist with adept background in health economics.

\section{Corresponding author}

Correspondence to Chidozie Emmanuel Mbada

\section{Acknowledgements}

We would like to thank all the students who participated in this study and the Heads of Department of the training institutions that granted access for this study to be conducted. We also thank the Association of Clinical and Academic Physiotherapists of Nigeria (ACAPN) for providing valuable feedback at the presentation at ACAPN Conference in 2017.

\section{Abbreviations}

OAU: Obafemi Awolowo University

Ul: University of Ibadan

UNILAG: University of Lagos

SPPBQ: Students Perception of Professor Bullying Questionnaire

\section{References}

1. Spiers C. Tolley's Managing stress in the work place. Croydon; Lexis Nexis. 2003

2. British Medical Association Stopping harassment and bullying at work. British Medical Association. Available at: www.bma.org.uk/practical-support-at-work/doctors-well-being/bullying-andharassment. Assessed July, 2017. 
3. Namie G. US hostile workplace survey 2000. InLabor Day Meeting.

4. Keashly L, Nowell B. Workplace bullying and conflict resolution.Bullying and emotional abuse in the workplace: International research and practice perspectives. 2003; 339-358.

5. Einarsen S, Hoel H, Notelaers G. Measuring exposure to bullying and harassment at work: Validity, factor structure and psychometric properties of the Negative Acts Questionnaire-Revised. Work Stress. 2009; 23, 24-44.

6. Tepper BJ. Consequences of abusive supervision.Academy of management journal. 2000; 43(2), 178-190.

7. Einarsen S, Skogstad A. Bullying at work: Epidemiological findings in public and private organizations. European journal of work and organizational psychology, 1996; 5(2), 185-201.

8. Laposa JM, Alden LE, Fullerton LM: Work stress and posttraumatic stress disorder in ED nurses/ personnel. J Emerg Nurs. 2003; 29 (1):23-28.

9. Gillespie GL, Gates DM, Miller M, Howard PK: Violence against healthcare workers in a pediatric. . Adv Emerg Nurs J. 2010; 32(1):68-82

10. Gates D, Gillespie G, Succop P: Violence against nurses and its impact on stress and productivity. Nurs Econ. 2011; 29(2): 59-67.

11. Miedema B, Tatemichi S, Hamilton R, Lambert-Lanning A, Lemire F, Manca DP, Ramsden VR: Effect of colleague and coworker abuse on family physicians in Canada. Can Fam Physician. 2011; 57(12):1424-31.

12. Malinauskiene V, Bernotaite L. Workplace bullying and posttraumatic stress symptoms among family physicians in Lithuania. Int J. Occup Med Environ Health. 2014; 27 (6):919-932

13. Heponiemi T, Kouvonen A, Virtanen M, Vänskä J, Elovainio $M$. The prospective effects of workplace violence on physicians' job satisfaction and turnover intentions: the buffering effect of job control. BMC Health Serv Res. 2014;14(1):19.

14. VogelpohI DA, Rice SK, Edwards ME, Bork CE. New graduate nurses' perception of the workplace: have they experienced bullying? Journal of Professional Nursing. 2013; 29(6), 414-422.

15. Allen BC, Holland P, Reynolds R. The effect of bullying on burnout in nurses: the moderating role of psychological detachment.Journal of Advanced Nursing. 2015; 71(2), 381-390.

16. Reynolds G, Kelly S, Singh-Carlson S. Horizontal hostility and verbal violence between nurses in the perinatal arena of health care.Nursing Management. 2014; 20(9).

17. Azodo CC, Ezeja EB, Ehikhamenor EE. Occupational violence against dental professionals in southern Nigeria.African health sciences. 2011;11(3).

18. Rodwell J, Demir D. Psychological consequences of bullying for hospital and aged care nurses.International nursing review. 2012; 59(4), 539-546.

19. Hinduja S, Patchin JW. Bullying, cyberbullying, and suicide.Archives of suicide research. 2010; 14(3), 206-221. 
20. Dehue F, Bolman C, Völlink, T. Cyberbullying: Youngsters' experiences and parental perception.CyberPsychology \& Behavior. 2008; 11(2), 217-223.

21. United Nations Educational, Scientific and Cultural Organization (UNESCO). School violence and bullying: Global status report. 2017. Available at https://unesdoc.unesco.org/ark:/48223/pf0000246970.

22. Respecting others: Bullying around race, religion and culture. Respecting others: Bullying around race, religion and culture. Guidance document No: 051/2011

23. Scherr T, Larson J. Bullying dynamics associated with race, ethnicity, and immigration status. Handbook of bullying in schools: An international perspective. 2009; 223-234.

24. Bradshaw CP, Waasdorp TE, O'Brennan LM, Gulemetova M. Teachers' and education support professionals' perspectives on bullying and prevention: Findings from a National Education Association study. School psychology review. 2013; 42(3), 280-297.

25. Rautio A, Sunnari V, Nuutinen M, Laitala M: Mistreatment of university students most common during medical studies. BMC Med Educ. 2005; 5:36.

26. Fried JM, Vermillion M, Parker NH, Uijtdehaage S. Eradicating medical student mistreatment: a longitudinal study of one institution's efforts. Acad Med. 2012;87(9):1191-1198.

27. Francis R. The mid Sta ffor dshir e NHS foundation trust public inquiry report of the mid Staffordshire NHS foundation trust public inquiry executive summary. Presented at the: 2013. www.midstaffspublicinquiry.com. Accessed May 3, 2019.

28. Timm A. It would not be tolerated in any other profession except medicine: survey reporting on undergraduates' exposure to bullying and harassment in their first placement year. BMJ Open. 2014;4(7):e005140.

29. Mukhtar F, Daud S, Manzoor I, et al. Bullying of Medical Students. J Coll Physicians Surg Pakistan . 2010;20(12):814-818. https://jcpsp.pk/archive/2010/Dec2010/10.pdf.

30. Hunt C, Marini ZA. Incivility in the practice environment: A perspective from clinical nursing teachers. Nurse Educ Pract. 2012;12(6):366-370.

31. Goldberg E, Beitz J, Wieland D, Levine C. Social bullying in nursing academia. Nurse Educ. 2013; 38(5): 191-7.

32. Pottinger AM, Trotman-Ewards $\mathrm{H}$, Younger $\mathrm{N}$ : Detecting depression during pregnancy and associated lifestyle practices and concerns among women in a hospital-based obstetric clinic in Jamaica. Gen Hosp Psychiatry. 2009:31:254-261

33. Twemlow SW, Biggs BK, Nelson TD, Vernberg EM, Fonagy P, Twemlow SW. Effects of participation in a martial arts-based antibullying program in elementary schools. Psychol Sch. 2008;45(10).

34. Chapell M, Case D, De la Cruz C, Ferrell J, Forman J, Lipkin R, Newsham M, Sterling, Whittaker S: Bullying in College by Students and Teachers. Adolescence 2004; 39 (153): 53-64.

35. Olweus D, Limber SP. Bullying in school: Evaluation and dissemination of the Olweus Bullying Prevention Program. Am J Orthopsychiatry. 2010;80(1):124-134. 
36. Brendgen M, Wanner B, Vitaro F, Bukowski WM, Tremblay RE. Verbal abuse by the teacher during childhood and academic, behavioral, and emotional adjustment in young adulthood. J Educ Psychol. 2007;99(1):26-38.

37. Pottinger AM, Stair AG. Bullying of students by teachers and peers and its effect on the psychological well-being of students in jamaican schools. J Sch Violence. 2009;8(4):312-327.

38. Twemlow SW, Fonagy P, Sacco FC, Brethour JR. Lecturers who bully students: A hidden trauma. Int J Soc Psychiatry. 2006; 52:187-198.

39. Wilson JH, Ryan RG, Pugh J. Professor-student rapport scale predicts student outcomes. Teach Psychol. 2010; 37:246-25

40. Seager A. Workplace bullying of physiotherapists in Ireland: what actions do victims take? Physiother Ireland. 2004;25:3-13.

41. Whiteside D, Stubbs B, Soundy A. Physiotherapy students' experiences of bullying on clinical internships: a qualitative study. Physiotherapy. 2014;100(1):41-46.

42. Ogbonnaya GU, Ukegbu AU, Aguwa EN, Emma-Ukaegbu U. A study on workplace violence against health workers in a Nigerian tertiary hospital. Nigerian journal of medicine: journal of the National Association of Resident Doctors of Nigeria. 2012;21(2):174-9.

43. Mayer $\mathrm{CH}$, Viviers R, Tonelli L. 'The fact that she just looked at me...'-Narrations on shame in South African workplaces. SA Journal of Industrial Psychology. 2017;43(1):1-0.

44. Aduba JN. Human Rights and Social Justice in Nigeria: Issues, Dilemma and Options, in A. U. Kalu \& Y. Osinbajo (eds.), Perspectives on Human Rights(Nigerian Federal Ministry of Justice, 1992, p. 220), pp. 229-231.

45. Adenrele AR, Olugbenga OM. Challenges of Human Rights Abuses in Nigerian Democratic Governance-Which Way Forward?. Journal of Social Economics Research. 2014; 1(5), 87-96.

46. Yamane T. Research Methods: Determination of Sample Size. 1967.

47. Marraccini, Marisa E, College Students' Perceptions of Professor Bullying. Open Access Master's Theses. Paper 9. https://digitalcommons.uri.edu/theses/9. 2013.

48. Marraccini ME, Weyandt LL, Rossi JS. College students' perceptions of professor/instructor bullying: questionnaire development and psychometric properties. Journal of American college health. 2015; 63(8), 563-572.

49. Clarke C, Kane D, Rajacich D, Lafreniere K: Bullying in Undergraduate Clinical Nursing Education. J Nurs Educ. 2012; 51(5), 269-276.

50. Celik SS, Bayraktar N: A study of nursing student abuse in Turkey. J Nurs Educ. 2004; 43(7), 330-6.

51. Foster B, Mackie B, Barnett N. Bullying in the health sector: a study of bullying of nursing students. New Zealand Journal of Employment Relations, 2004; 29(2), 67-83.

52. Cooper J, Walker J, Askew R, Robinson J, McNair M: Students' perceptions of bullying behaviours by nursing faculty. Issues in Educational Research. 2011; 21(1), 1-21. 
53. Stevenson, K, Randle, J, Grayling I. Inter-group conflict in health care: UK students' experiences of bullying and the need for organizational solutions. The Online Journal of Issues in Nursing, 2006; 11(2), 5-6.

54. Palaz, S. Turkish nursing students' perceptions and experiences of bullying behavior in nursing education. J Nurs Educ Pract. 2013.391):23-30

55. Onimisi Trend of Human Right Abuse in Nigeria: 1996-2013. 2018

56. Greene MB. Bullying in schools: A plea for measure of human rights. Journal of Social Issues. 2006; 62(1), 63-79

57. United Nations Educational, Scientific and Cultural Organization (UNESCO). Review of homophobic bullying in educational institutions. 2012. Available at https://unesdoc.unesco.org/ark:/48223/pf0000215708

58. Judd K, Easteal P. Media reportage of sexual harassment: the (in) credible complainant.Denning LJ. $2013 ; 25,1$.

59. McEvoy A. Teachers who bully students: Patterns and policy implications. InHamilton fish institute's persistently safe schools conference. 2005.

60. Foster B, Mackie B, Barnett N. Bullying in the health sector: A study of bullying of nursing students.New Zealand Journal of Employment Relations. 2004; 29(2), 67.

61. Fafunwa, A. Learning among peers. Akure: Satellite Publications, 2004.

62. Farrant JS. Principles and practice of education: 19th Impression.Essex England: Longman Group UK Ltd. 2004.

63. Lukman AA, Hamadi AA. Disciplinary measures in Nigerian senior secondary schools: Issues and prospects.IOSR Journal of Research and Method in Education. 2014. 4(3), 11-17.

64. Alhassan AB. School corporal punishment in Ghana and Nigeria as a method of discipline: A psychological examination of policy and practice.Journal of Education and Practice. 2013; 4(27), 137-147.

65. Nakpodia ED. Teachers' disciplinary approaches to students' discipline problems in Nigerian secondary schools. International NGO Journal. 2010; 5(6), 144-151.

66. Iguh NA, Nosike O. An examination of the child rights protection and corporal punishment in Nigeria.Nnamdi Azikiwe University Journal of International Law and Jurisprudence. 2011; 2.

67. Hoel H, Giga SI, Davidson MJ. Expectations and realities of student nurses' experiences of negative behavior and bullying in clinical placement and the influences of socialization processes. Health Serv Manage Res. 2007; 20, 270-278.

68. Hall J. Dispelling desperation in nursing education. Nurs Outlook. 2016: 52, 147-154.

69. Salin D. ays of Explaining Workplace Bullying: A Review of Enabling, Motivating, and Precipitating Structures and Processes in the Work Environment. Hum Relations. 2003;56(10):1213-1232.

\section{Tables}


Table 1: Socio-Demographic Characteristics of the Respondents

\begin{tabular}{|c|c|c|c|c|c|c|}
\hline Variable & $\begin{array}{l}\text { OAU } \\
\mathrm{n}(\%)\end{array}$ & $\begin{array}{l}\text { UI } \\
\mathrm{n}(\%)\end{array}$ & $\begin{array}{l}\text { UNILAG } \\
\mathrm{n}(\%)\end{array}$ & $\mathrm{C} 2$ & $\mathrm{p}$-value & $\begin{array}{l}\text { All respondents } \\
\mathrm{n}(\%)\end{array}$ \\
\hline \multicolumn{7}{|l|}{ Gender } \\
\hline Male & $55(57.3)$ & $17(34.0)$ & $35(47.9)$ & 7.175 & 0.028 & $107(48.9)$ \\
\hline Female & $41(42.7)$ & $33(66.0)$ & $38(52.1)$ & & & $112(51.1)$ \\
\hline \multicolumn{7}{|l|}{ Age } \\
\hline$>20$ & $2(2.08)$ & $6(12.0)$ & $1(1.37)$ & & & $9(4.11)$ \\
\hline $20-25$ & $91(94.8)$ & $44(88.0)$ & $72(98.6)$ & 14.067 & 0.007 & $207(94.5)$ \\
\hline$<25$ & $3(3.13)$ & $0(0.00)$ & $0(0.00)$ & & & $3(1.37)$ \\
\hline \multicolumn{7}{|l|}{ Ethnicity } \\
\hline Yoruba & $85(88.5)$ & $44(88.0)$ & $59(80.8)$ & & & $188(85.8)$ \\
\hline Igbo & $10(10.4)$ & $5(10.0)$ & $12(16.4)$ & 2.493 & 0.646 & $27(12.3)$ \\
\hline Others & $1(1.04)$ & $1(2.00)$ & $2(2.74)$ & & & $4(1.83)$ \\
\hline \multicolumn{7}{|l|}{ Religion } \\
\hline Christianity & $83(86.5)$ & $41(82.0)$ & $51(69.9)$ & & & $175(79.8)$ \\
\hline Islam & $6(6.25)$ & $6(12.0)$ & $10(13.7)$ & 8.510 & 0.075 & $22(10.1)$ \\
\hline Others & $7(7.29)$ & $3(6.00)$ & $12(16.4)$ & & & $22(10.1)$ \\
\hline \multicolumn{7}{|c|}{ Educational Level } \\
\hline \multirow[t]{2}{*}{500} & $51(53.1)$ & $29(58.0)$ & 29(39.7) & 4.733 & 0.094 & $109(49.8)$ \\
\hline & $45(46.9)$ & $21(42.0)$ & $44(60.3)$ & & & $110(50.2)$ \\
\hline \multicolumn{7}{|l|}{ Marital Status } \\
\hline Single & $94(97.9)$ & $50(100)$ & $71(97.3)$ & 1.305 & 0.521 & $215(98.2)$ \\
\hline Married & $2(2.08)$ & $0(0.00)$ & $2(2.74)$ & & & $4(1.83)$ \\
\hline
\end{tabular}

OAU- Obafemi Awolowo University; UI- University of Ibadan; UNILAG- University of Lagos.

Table 2: Frequency Distribution on Adequate Policy and Support on Bullying in University 
Institution

$\begin{array}{llllll}\text { OAU } & \text { UI } & \text { UNILAG } & \text { C2 } & \text { p- } & \text { All } \\ \mathrm{n}(\%) & \mathrm{n}(\%) & \mathrm{n}(\%) & & \text { value } & \text { respondents } \\ & & & & & \mathrm{n}(\%)\end{array}$

Policy on bully

$\begin{array}{lllllll}\text { Yes } & 36(37.5) & 15(30.0) & 33(45.2) & 6.558 & 0.161 & 84(38.5) \\ \text { No } & 60(62.5) & 35(70.0) & 40(54.8) & & & 135(61.6)\end{array}$

Availability of support

on bullying

Yes

No

$$
\begin{array}{llllll}
41(42.7) & 24(48.0) & 33(45.2) & 2.220 & 0.695 & 98(44.7) \\
55(57.3) & 26(52.0) & 40(54.8) & & & 121(55.3)
\end{array}
$$

OAU- Obafemi Awolowo University; UI- University of Ibadan; UNILAG- University of Lagos.

Table 3: Frequency Distribution on Bullying Characteristics among the Respondents 
Respondents Institution

$\begin{array}{ccc}\text { OAU } & \text { UI } & \text { UNILAG } \\ n(\%) & n(\%) & n(\%)\end{array}$

C2 pvalue respondent $\mathrm{n}(\%)$

Ever seen student been

bullied?

$\begin{array}{cllllll}\text { Yes } & 91(94.8) & 47(94.0) & 69(94.5) & 0.040 & 0.980 & 207(94.5) \\ \text { No } & 5(5.21) & 3(6.00) & 4(5.48) & & & 12(5.48)\end{array}$

Have you ever

experienced bullying?

$\begin{array}{llll}\text { Yes } & 95(99.0) & 49(98.0) & 72(98.6) \\ \text { No } & 1(1.04) & 1(2.00) & 1(1.37)\end{array}$

$0.223 \quad 0.894 \quad 216(98.6)$

$3(1.37)$

Attempts by student to

stop lecturer bullying?

$\begin{array}{cllllll}\text { Yes } & 1(1.04) & 0(0.00) & 0(0.00) & 1.287 & 0.525 & 1(0.46) \\ \text { No } & 95(98.9) & 50(100) & 73(100) & & & 218(99.5)\end{array}$

Have you been bullied in present level?

\begin{tabular}{|c|c|c|c|c|c|c|}
\hline Yes & $95(98.9)$ & $49(98.0)$ & $73(100)$ & 1.343 & 0.511 & $217(99.1)$ \\
\hline No & $1(1.04)$ & $1(2.00)$ & $0(0.00)$ & & & $2(0.91)$ \\
\hline
\end{tabular}

Ever stopped or attempted to stop bullying other students?

$\begin{array}{clllll} & 0(0.00) & 0(0.00) & 0(0.00) & - & - \\ \text { Yes } & 96(100) & 50(100) & & & 219(100) \\ \text { No } & & & & \end{array}$

$73(100)$

OAU- Obafemi Awolowo University; UI- University of Ibadan; UNILAG- University of Lagos

Table 4: Test of Association between Lifetime Prevalence of Bullying and Socio-Demographic Characteristics of Respondents 


\begin{tabular}{|c|c|c|c|c|}
\hline \multirow[t]{2}{*}{ Variables } & \multicolumn{3}{|c|}{ Bullying Response } & \multirow[b]{2}{*}{$\mathrm{p}$-value } \\
\hline & $\begin{array}{l}\text { YES } \\
\mathrm{n}(\%)\end{array}$ & $\begin{array}{l}\text { NO } \\
\text { n(\%) }\end{array}$ & $\mathrm{C} 2$ & \\
\hline \multicolumn{5}{|l|}{ Gender } \\
\hline Male & $104(47.5)$ & $3(1.37)$ & 3.184 & 0.07 \\
\hline Female & $112(51.1)$ & $0(0.00)$ & & \\
\hline \multicolumn{5}{|l|}{ Age } \\
\hline$<20$ & $9(4.11)$ & $0(0.00)$ & 0.176 & 0.91 \\
\hline $20-25$ & $204(93.2)$ & $3(1.37)$ & & \\
\hline$>25$ & $3(1.37)$ & $0(0.00)$ & & \\
\hline \multicolumn{5}{|l|}{ Ethnicity } \\
\hline Yoruba & $185(84.5)$ & $3(1.37)$ & 0.502 & 0.77 \\
\hline Igbo & $27(12.3)$ & $0(0.00)$ & & \\
\hline Others & $4(1.83)$ & $0(0.00)$ & & \\
\hline \multicolumn{5}{|l|}{ Religion } \\
\hline Christianity & $174(79.5)$ & $1(0.46)$ & 10.84 & 0.060 \\
\hline Islam & $20(9.13)$ & $2(0.91)$ & & \\
\hline Others & $22(10.1)$ & $0(0.00)$ & & \\
\hline \multicolumn{5}{|l|}{ University } \\
\hline OAU & $95(43.4)$ & $1(0.46)$ & 0.223 & 0.894 \\
\hline UI & $49(22.4)$ & $1(0.46)$ & & \\
\hline UNILAG & $72(32.9)$ & $1(0.46)$ & & \\
\hline \multicolumn{5}{|l|}{ Level } \\
\hline 400 & $108(49.3)$ & $1(0.46)$ & 0.329 & 0.566 \\
\hline 500 & 108(49.3) & $2(0.91)$ & & \\
\hline \multicolumn{5}{|l|}{ Marital Status } \\
\hline Single & $213(97.3)$ & $2(0.91)$ & 16.839 & 0.064 \\
\hline Married & $3(1.37)$ & $1(0.46)$ & & \\
\hline
\end{tabular}

OAU- Obafemi Awolowo University; UI- University of Ibadan; UNILAG- University of Lagos.

Table 5: Test of Association between Point Prevalence of Bullying and Socio-Demographic Characteristics of Respondents 


\begin{tabular}{|c|c|c|c|c|}
\hline \multirow[t]{2}{*}{$\overline{\text { Jariables }}$} & \multicolumn{2}{|c|}{ Bullying Response } & \multirow[b]{2}{*}{$\mathrm{C} 2$} & \multirow[b]{2}{*}{ p-value } \\
\hline & $\begin{array}{r}\text { YES } \\
\text { n(\%) }\end{array}$ & $\begin{array}{l}\text { NO } \\
\text { n(\%) }\end{array}$ & & \\
\hline \multicolumn{5}{|l|}{ Jender } \\
\hline Male & $106(48.4)$ & $1(0.46)$ & 0.001 & 0.974 \\
\hline Female & $111(50.7)$ & $1(0.46)$ & & \\
\hline \multicolumn{5}{|l|}{ tge } \\
\hline$<20$ & $9(4.11)$ & $0(0.00)$ & 0.117 & 0.94 \\
\hline $20-25$ & 205(93.6) & $2(0.91)$ & & \\
\hline$>25$ & $3(1.37)$ & $0(0.00)$ & & \\
\hline \multicolumn{5}{|l|}{ Ethnicity } \\
\hline Yoruba & 186(84.9) & $2(0.91)$ & 0.333 & 0.847 \\
\hline Igbo & $27(12.3)$ & $0(0.00)$ & & \\
\hline Others & $4(1.83)$ & $0(0.00)$ & & \\
\hline \multicolumn{5}{|l|}{ Religion } \\
\hline Christianity & $174(79.5)$ & $1(0.46)$ & 3.636 & 0.162 \\
\hline Islam & $22(10.1)$ & $0(0.00)$ & & \\
\hline Others & $4(1.83)$ & $1(0.46)$ & & \\
\hline \multicolumn{5}{|l|}{ Jniversity } \\
\hline OAU & $95(43.4)$ & $1(0.46)$ & 1.343 & 0.511 \\
\hline UI & $49(22.4)$ & $1(0.46)$ & & \\
\hline UNILAG & $73(33.3)$ & $0(0.00)$ & & \\
\hline \multicolumn{5}{|l|}{ _evel } \\
\hline 400 & 108(49.3) & $1(0.46)$ & 0.000 & 0.995 \\
\hline 500 & $109(49.8)$ & $1(0.46)$ & & \\
\hline \multicolumn{5}{|l|}{ Marital Status } \\
\hline Single & $213(97.3)$ & $2(0.91)$ & 0.038 & 0.846 \\
\hline Married & $4(1.83)$ & $0(0.00)$ & & \\
\hline
\end{tabular}

OAU- Obafemi Awolowo University; UI- University of Ibadan; UNILAG- University of Lagos.

\section{Figures}




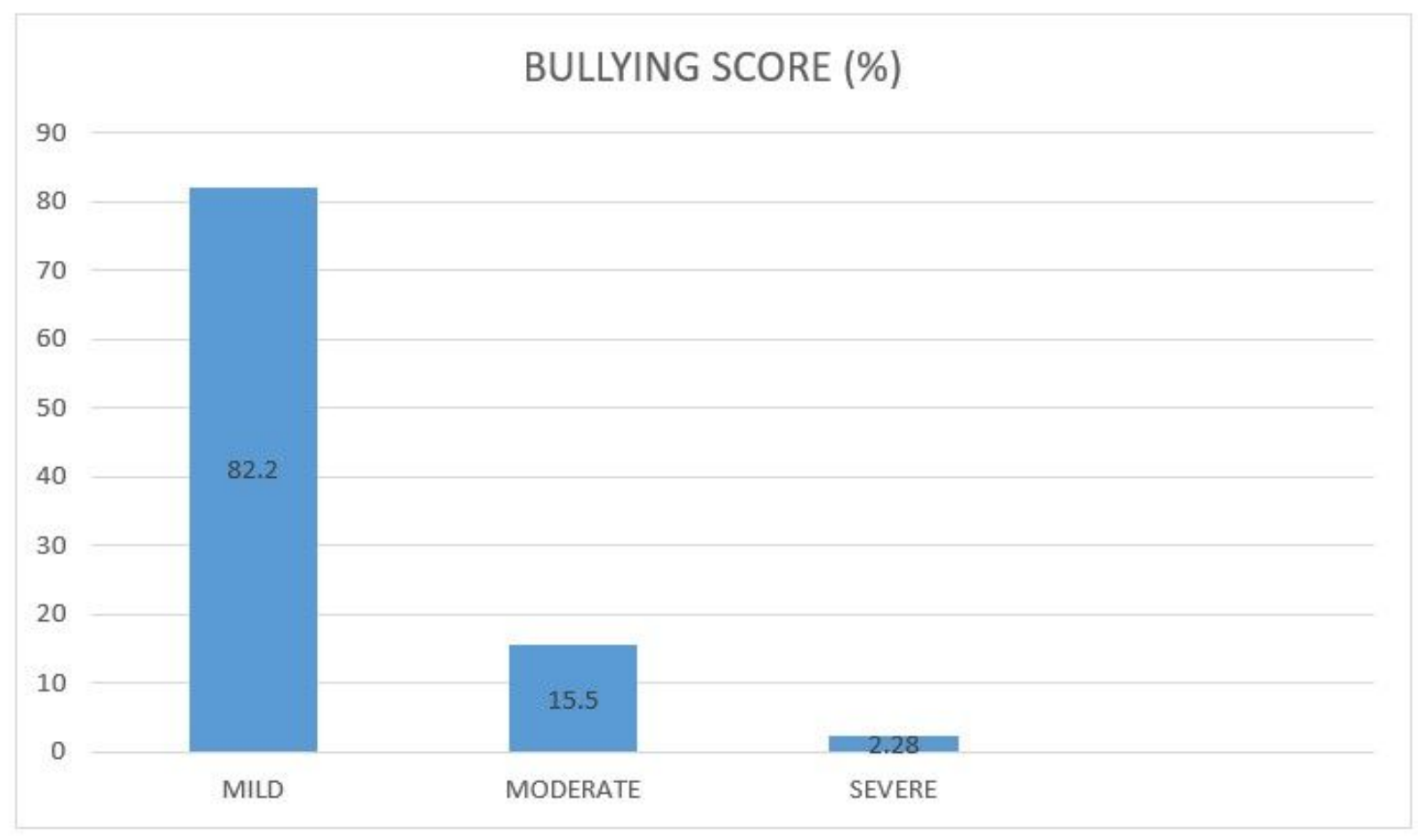

\section{Figure 1}

Bullying Score of all Respondents

\section{Supplementary Files}

This is a list of supplementary files associated with this preprint. Click to download.

- Appendix.docx 